\section{The Germination Responses of Five Bermudagrass Cultivars to Seedcoating and Temperature}

\author{
Gregg C. Munshaw ${ }^{1}$ \\ Department of Plant and Soil Science, 1405 Veterans Drive, University of \\ Kentucky, Lexington, KY 40546
}

John M. Layton

School of Agriculture and Natural Resources, Abraham Baldwin Agricultural College, 2802 Moore Highway, Tifton, GA 31793

Barry R. Stewart and H. Wayne Philley

Department of Plant and Soil Sciences, Mississippi State University, 32 Creelman Street, Mississippi State, MS 39762

Jeffrey S. Beasley

School of Plant Environmental, and Soil Sciences, Louisiana State University Agricultural Center, Baton Rouge, LA 70803

\section{Rocky W. Lemus \\ Department of Plant and Soil Sciences, Mississippi State University, 32 Creelman Street, Mississippi State, MS 39762}

Additional index words. AOSA, Cynodon dactylon, growth chamber

\begin{abstract}
As turfgrass quality of seeded bermudagrass (SB) [Cynodon dactylon (L.) Pers.] cultivars has increased over the past 20 years, so has their use. Improved SB cultivars offer ease of establishment and convenience of storage while providing an economic advantage over vegetative propagation. Currently, most improved seeded cultivars are marketed with a seedcoating unique to each seed company. However, germination of some of the new cultivars is not ideal. The objectives of this study were to determine commercial coating effects on germination, compare germination among cultivars, and evaluate the effect of temperature on germination of five bermudagrass cultivars. 'Princess-77', 'Riviera', 'Transcontinental', and 'Yukon' were selected for a series of 21-day germination studies with 'Arizona Common' included as a standard cultivar. The study compared two seed lots of coated and uncoated samples of the five cultivars for germination response to six temperature regimes. Cumulative count intervals occurred on Day 7, Day 14, and Day 21. Overall, commercial seedcoating did not significantly affect SB germination. However, both temperature regime and cultivar were significant factors. Germination percentage was greatest with either the $35 / 25^{\circ} \mathrm{C}$ or the $30 / 20^{\circ} \mathrm{C}$ temperature regimes. 'Riviera' exhibited the lowest overall germination, whereas 'Transcontinental' and 'Arizona Common' exhibited the highest.
\end{abstract}

In recent years, many improved seeded bermudagrass [Cynodon dactylon (L.) Pers.] cultivars have become commercially available. As the turfgrass quality of several SB cultivars have reached the level of vegetative industry standards (Morris, 2002), the use of SB has increased. With the new focus on improved SB cultivars, germination characteristics have become increasingly important to improve stand establishment and overall turf quality. Bermudagrass can germinate and grow in a wide range of environments from the transition zone to tropical climates (Duble, 1989), and improved SB cultivars continue to

Received for publication 22 Oct. 2012. Accepted for publication 6 Aug. 2014.

${ }^{1}$ To whom reprint requests should be addressed; e-mailgcmunshaw@uky.edu.
(Steinbauer and Grigsby, 1957) and may be the result of structural changes within the seed that cause a change in the balance between germination inhibitors and promoters (Copeland and McDonald, 2001).

Although irradiance is not an absolute requirement for germination of many species, bermudagrass has improved germination in the presence of light. Morinaga (1926) first established the benefits of irradiance regarding bermudagrass germination by demonstrating how a $24-\mathrm{h}$ photoperiod provided a $56 \%$ improvement in germination over seeds in constant darkness. Additionally, Ahring and Todd (1978) successfully performed germination experiments with a photoperiod of $8 \mathrm{~h}$. Currently, the Association of Official Seed Analysts (AOSA) recommends an 8-h photoperiod for all germination studies involving C. dactylon var. dactylon (AOSA, 2009). Bermudagrass plantings in the United States commonly occur between the vernal equinox in March and the autumnal equinox in September. This indicates that photoperiod during a typical planting season exceeds 12 h (Bonan, 2002).

Bryan (1918) first described the difficulty of obtaining adequate germination of bermudagrass seed and demonstrated improved germination results through sulfuric acid treatments. Scarification of the seedcoat by chemical or physical processes can improve imbibition and decrease embryonic inhibitors of germination. Bermudagrass seed has traditionally demonstrated decreased germination, and in recent studies, time to germination varied significantly among cultivars (Patton et al., 2004b; Richardson et al., 2004b). Additionally, in a recent germination study, Sandlin et al. (2006) reported low germination of several cultivars at various temperatures as well as significant differences among cultivars regarding germination.

Seedcoating has been a common practice in many crops but until recently has not been extensively used on turfgrasses. Several coatings have been tested on grass seed germination, including lime (Scott, 1975; Vartha and Clifford, 1973), cytokinin (Greipsson, 1999), fungicides (Newell et al., 1999; Richardson and Hignight, 2010), fertilizer (Bruneau et al., 1989), talc (Scott, 1975), and starch-based polymers (Leinauer et al., 2010; Richardson and Hignight, 2010) to varying levels of success. Reports on bermudagrass seedcoating are rare. Published reports show either no benefit from coating bermudagrass seed (Leinauer et al., 2010; Serena et al., 2012) or reduced germination from seedcoated with fertilizer (Hickey and Engleke, 1983). No research was found that tested the effect of commercially applied seedcoatings on bermudagrass germination.

Two major hypotheses have been put forth concerning differences in SB germination between cultivars: 1) genetic differences; 2) seed preparation such as seedcoatings; or 3 ) a combination of the two. Currently, improved SB cultivars are available almost exclusively with a commercially applied seedcoating of various materials depending on the seed 
producer. Although it is known that seedcoatings improve ease of planting and seed supply demands while decreasing planting rate error (Kaufman, 1991), it is not well established whether seedcoatings influence bermudagrass germination. Thus, the objectives of this study were to 1) compare germination percentages of five SB cultivars; 2) evaluate the effect of various temperature regimes on germination of five SB cultivars; and 3) determine whether seedcoating influences germination. Because germination and stand establishment are key factors in selecting a SB cultivar, elucidating a cultivar-specific optimal temperature regime for germination, establishing effects of a seedcoating on germination, and identifying cultivars with increased germination potential should provide valuable information to turfgrass managers.

\section{Materials and Methods}

Seed treatment. 'Arizona Common' (Seeds West, Inc., Maricopa, AZ), 'Princess-77' (Seeds West, Inc., Maricopa, AZ), 'Riviera' (Johnston's Seed Company, Enid, OK), 'Transcontinental' (Pure-Seed Testing, Hubbard, OR), and 'Yukon' (Seed Research of Oregon, Halsey, OR; Johnston's Seed Company) were evaluated in a germination experiment. Coating effects on seeded bermudagrass germination were examined at six different temperature regimes.

Fresh samples of coated and uncoated bermudagrass seed were obtained from each seed source. Coated and uncoated samples came from the same lot, and seed from two lots were obtained for each cultivar. Seeds were stored in sealed plastic bags at room temperature $\left(22{ }^{\circ} \mathrm{C}\right)$ before germination experiments. Seed samples were tested exactly as supplied by each seed company, irrespective of hull status. For this study, 'Princess-77' and 'Arizona Common' seed were coated with a green commercial coating at a 1:1 seed-to-coating weight ratio and composition of the coating is proprietary (C. Rodgers, personal communication, 2007). 'Riviera' seed was coated with a purple commercial seedcoating in a 1:1 ratio; the coating contains $46 \% \mathrm{CaCO}_{3}$ plus fludioxonil and mefenoxam (M. Hills, S. Barclay, personal communication, 2007). The 'Transcontinental' selected for this study contained a gray experimental coating composed of $\mathrm{CaCO}_{3}$ plus zinc (J. Frelich, personal communication, 2007). 'Yukon' seed was coated with a blue seedcoating in a 1:1 ratio; the composition of the coating is $45.5 \%$ calcium carbonate, $2.5 \%$ monocalcium phosphate, and $2.0 \%$ calcium lignosulfonate (M. Hills, personal communication, 2007).

Seed samples were initially aspirated through a number 16 U.S.A. standard testing sieve (Fisher Scientific Company, Pittsburgh, PA) before counting. Seeds were counted into allotments of 50 by a photodetective electronic seed counter (The Old Mill Company, Savage, MD). Calibration of the electronic counter was verified by five test counts with each cultivar and random sampling during counting.
Sterile petri dishes measuring $100 \mathrm{~mm} \times$ $15 \mathrm{~mm}$ (Kord Products, Inc., Brampton, Ontario, Canada) were used for the germination study. Substrata were two circles of Whatman \#1 qualitative filter paper (Whatman International, Maidstone, U.K.). Filter paper was moistened with distilled water before a single plot of 50 seeds was placed in each petri dish. Seeds were then watered before being placed in the germination chambers. Further watering of seeds took place daily or as needed to maintain filter paper moisture.

Six germination chambers (Percival Scientific, Boone, IA) were used for the study. Chambers were randomly set with daytime temperatures $10{ }^{\circ} \mathrm{C}$ higher than night temperatures (Ahring and Todd, 1978; ISTA, 2004). Day/night temperatures consisted of $45 / 35,40 / 30,35 / 25,30 / 20,25 / 15$, and $20 / 10{ }^{\circ} \mathrm{C}$. Bermudagrass is most commonly planted between the vernal and autumnal equinox when photoperiod meets or exceeds $12 \mathrm{~h}$ in the northern hemisphere (Bonan, 2002), so a daylength of $12 \mathrm{~h}$ was chosen (Evers and Parsons, 2010). Fluorescent lighting was supplied for a 12-h photoperiod. Illuminance was measured at 55 microEinsteins using an integrated quantum radiometer/photometer (LI-COR Incorporated, Lincoln, NE). Temperature calibration of the chambers was verified with mercury thermometers (Fisher Scientific Company). Temperatures were maintained within $\pm 1{ }^{\circ} \mathrm{C}$ of the targeted day or night temperature.

Germination and statistics. The statistical design to evaluate bermudagrass seed germination was a factorial design with three fixed effects with varying levels: bermudagrass cultivar, temperature regimen, and seedcoating. Seed lot was considered a random factor. Four hundred coated and 400 uncoated seeds (AOSA, 2009) of five bermudagrass cultivars from differing lots were tested for germination at six temperature regimes.

Seed germination was defined by the presence of both a radicle and plumule (AOSA, 2009; Barden et al., 1987; Campbell, 1993). Seed size and vigor were not considered. Per AOSA guidelines for bermudagrass seed, the length of each experiment was $21 \mathrm{~d}$ (AOSA, 2009). Counting of seedlings occurred at 7,14 , and $21 \mathrm{~d}$ after planting. Petri dishes were temporarily removed from the germination chambers during counting. Seedlings were extracted from petri dishes, counted, and then discarded.

Table 1. Analysis of variance results for seed lot, coating, temperature, and cultivar in a bermudagrass germination experiment at three count intervals (2008).

\begin{tabular}{lccr}
\hline & \multicolumn{3}{c}{ Count intervals (days) } \\
\cline { 2 - 4 } Effect & Day 7 & Day 14 & Day 21 \\
\hline Temperature & $<0.0001^{z}$ & $<0.0001$ & $<0.0001$ \\
Cultivar & $<0.0001$ & $<0.0001$ & $<0.0001$ \\
Seed lot (cultivar) & $<0.0001$ & $<0.0001$ & $<0.0001$ \\
Seed coating & 0.8846 & 0.1649 & 0.1757 \\
Temperature $\times$ cultivar & $<0.0001$ & $<0.0001$ & $<0.0001$ \\
Temperature $\times$ seed coating & $<0.0001$ & $<0.0001$ & $<0.0001$ \\
Cultivar $\times$ seed coating & $<0.0001$ & $<0.0001$ & $<0.0001$ \\
Temperature $\times$ cultivar $\times$ seed coating & 0.0015 & 0.0052 & 0.0059 \\
\hline
\end{tabular}

Germination data were analyzed using the GLIMMIX procedure of Statistical Analysis Software (SAS, Cary, NC) for each measurement date. Square root of germination percentages was arcsine transformed to normalize germination data for pairwise comparisons (Baldwin et al., 2009) with untransformed data reported. Because seedcoatings are proprietary and differed between some cultivars, statistical comparisons between coated and uncoated bermudagrass seed germination means across temperature regimes occurred only within each cultivar tested using Tukey's procedure at $P \leq$ 0.05 . Mean comparisons of bermudagrass seed germination across cultivars at various temperature regimes occurred only on uncoated seeds using Tukey's procedure at $P \leq 0.05$.

\section{Results}

Significance levels of main effects and their interactions at three count intervals are presented in Table 1. All main effects other than coating are highly significant at all three count intervals. Two-way interactions of temperature $\times$ cultivar and temperature $\times$ seedcoating were also highly significant $(P \leq 0.0001)$ at all three count intervals. Because there was a seedcoating $\times$ cultivar $\times$ temperature interaction, the 3-week germination results are presented separately for each cultivar in Table 2.

'Arizona Common'. Commercial coating had very little effect on the germination of 'Arizona Common' (Table 2). Within the $35 / 25{ }^{\circ} \mathrm{C}$ temperature regime, coated seed had less germination than uncoated seed; however, the difference was only significant at Day 7. The effect of coating resulted in no other differences at any other counting interval or temperature regime.

Temperature regime had a significant effect on the germination of 'Arizona Common'. At all three count intervals, in both coated and uncoated seed, the $35 / 25$ and $30 / 20{ }^{\circ} \mathrm{C}$ temperature regimes had the highest germination. The $20 / 10{ }^{\circ} \mathrm{C}$ temperature regime exhibited the lowest amount of germination with coated or uncoated seed at all count intervals. Temperature regime rankings for total germination (Day 21) of coated seed were as follows: $30 / 20=35 / 25>25 / 15>$ $40 / 30>45 / 35>20 / 10^{\circ} \mathrm{C}$. For uncoated seed, the rankings were as follows: $30 / 20=35 / 25=$ $25 / 15>40 / 30>45 / 35>20 / 10{ }^{\circ} \mathrm{C}$.

'Princess $77^{\prime}$ '. At the $40 / 30$ and $45 / 35^{\circ} \mathrm{C}$ temperature regimes, the commercial coating 


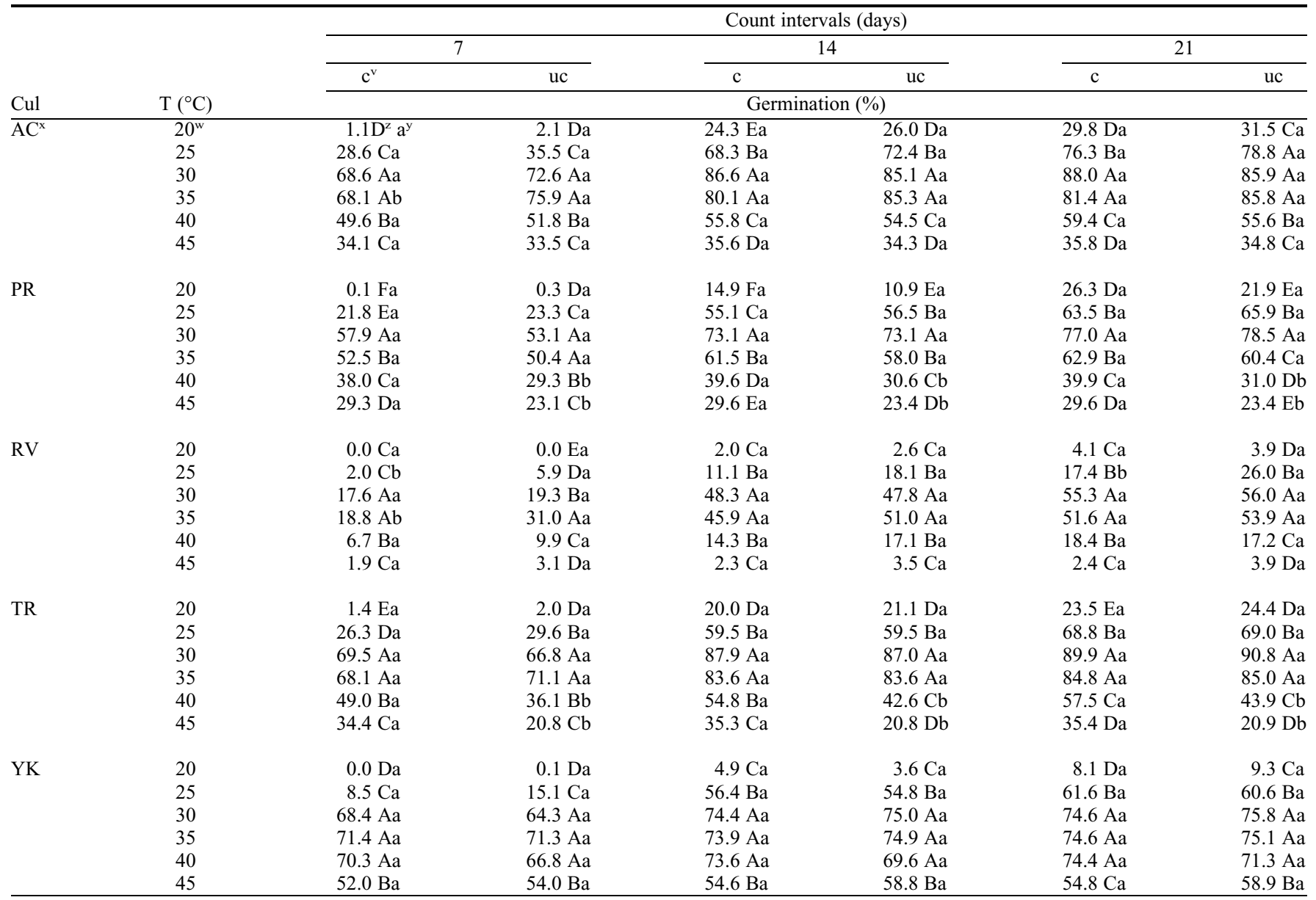

${ }^{\mathrm{z}}$ Values followed with different uppercase letters within the same column and cultivar (comparing temperatures within cultivar) are significantly different $(P=$ $0.05)$.

${ }^{y}$ Values followed with different lowercase letters within a row and count interval (comparing coated vs. uncoated seed) are significantly different $(P=0.05)$.

${ }^{\mathrm{x}} \mathrm{AC}=$ 'Arizona Common'; $\mathrm{PR}=$ 'Princess-77'; RV = 'Riviera'; TR = 'Transcontinental'; $\mathrm{YK}=$ 'Yukon'.

${ }^{w}$ Day/night temperature regimes $20 / 10 ; 25 / 15 ; 30 / 20 ; 35 / 25 ; 40 / 30 ; 45 / 35^{\circ} \mathrm{C}$.

${ }^{\mathrm{v}} \mathrm{c}=$ coated; $\mathrm{uc}=$ uncoated.

exhibited a significant positive effect on germination of 'Princess 77 ' at all three count intervals (Table 2). However, coating was not significant at any other counting interval or temperature regime.

Temperature regime had a significant effect on the germination of 'Princess 77'. For coated and uncoated seed at Day 7, the 30/20 and $35 / 25{ }^{\circ} \mathrm{C}$ temperature regimes exhibited the highest germination. However, for coated and uncoated seed at Day 21, the 30/20, $35 / 25$, and $25 / 15{ }^{\circ} \mathrm{C}$ temperature regimes had the highest germination. The $20 / 10{ }^{\circ} \mathrm{C}$ temperature regime exhibited the lowest amount of germination at Days 7 and 14 count intervals for coated and uncoated seed. The $20 / 10$ and $45 / 35^{\circ} \mathrm{C}$ temperature regimes exhibited the lowest germination at the 21-d count interval for coated and uncoated seed. Temperature regime rankings for total germination (Day 21) of coated seed were as follows: $30 / 20>25 / 15=35 / 25>40 / 30>$ $45 / 35=20 / 10{ }^{\circ} \mathrm{C}$. Uncoated seed temperature regime rankings were as follows: $30 / 20>$ $25 / 15>35 / 25>40 / 30>45 / 35=20 / 10{ }^{\circ} \mathrm{C}$.

'Riviera'. Commercial coating had a significant negative effect on germination of 'Riviera' at the Day 7 counting interval in both the $25 / 15$ and $35 / 25{ }^{\circ} \mathrm{C}$ temperature regimes (Table 2). At the Day 21 interval, only the $25 / 15{ }^{\circ} \mathrm{C}$ temperature regime showed a significant negative effect as a result of coating. No other counting interval or temperature regime showed differences resulting from coating.

Temperature regime had a significant effect on germination of 'Riviera'. In both coated and uncoated seed at all three counting intervals, the $30 / 20$ and $35 / 25^{\circ} \mathrm{C}$ temperature regimes showed the highest germination. The $20 / 10$ and $45 / 35{ }^{\circ} \mathrm{C}$ temperature regimes exhibited the lowest amount of germination with coated and uncoated seed at all three count intervals. Temperature rankings for total germination (Day 21) of coated seed were as follows: $30 / 20=35 / 25>40 / 30=25 / 15>$ $20 / 10=45 / 35{ }^{\circ} \mathrm{C}$. Temperature regime rankings for uncoated seed were as follows: $30 / 20=$ $35 / 25>25 / 15>40 / 30>20 / 10=45 / 35{ }^{\circ} \mathrm{C}$.

'Transcontinental'. Commercial coating had a significant positive effect on germination of 'Transcontinental' at all three counting intervals for both the $40 / 30$ and $45 / 35^{\circ} \mathrm{C}$ temperature regimes (Table 2). Coating showed no other differences at any other counting interval or temperature regime.
Temperature regime had a significant effect on germination of 'Transcontinental'. For both coated and uncoated seed, the $30 / 20$ and $35 / 25{ }^{\circ} \mathrm{C}$ temperature regimes exhibited the highest germination at all three counting intervals. The $20 / 10$ and $45 / 35{ }^{\circ} \mathrm{C}$ temperature regimes exhibited the lowest amount of germination with coated or uncoated seed at all count intervals. Temperature rankings for total germination (Day 21) for coated seed were as follows: $30 / 20=$ $35 / 25>25 / 15>40 / 30>45 / 35>20 / 10{ }^{\circ} \mathrm{C}$. For uncoated seed, the rankings were as follows: $30 / 20=35 / 25>25 / 15>40 / 30>$ $20 / 10=45 / 35^{\circ} \mathrm{C}$.

'Yukon'. Commercial coating did not have a significant effect on germination of 'Yukon' at any counting interval or temperature regime (Table 2).

Temperature regime had a significant effect on the germination of 'Yukon'. At all three count intervals, the $30 / 20,35 / 25$, and $40 / 30{ }^{\circ} \mathrm{C}$ regimes exhibited the highest germination for coated and uncoated seed. The $20 / 10{ }^{\circ} \mathrm{C}$ temperature regime exhibited the lowest amount of germination with both coated and uncoated seed at all count intervals. Temperature regime rankings for 


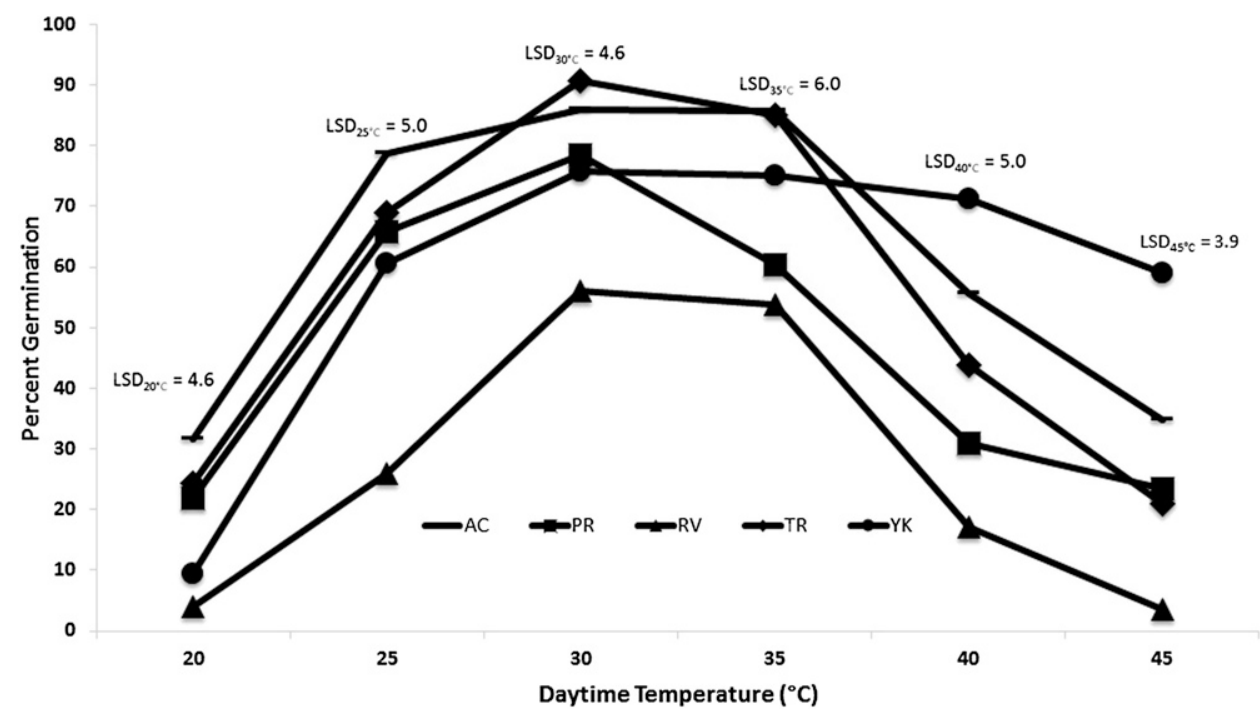

Fig. 1. Total germination of uncoated seed of five bermudagrass cultivars after $21 \mathrm{~d}$ under various temperature regimes. Day/night temperature regimes are $20 / 10$, 25/15, 30/20, 35/25, 40/30, 45/35 'C. AC = 'Arizona Common'; PR = 'Princess'; RV = 'Riviera'; TR = 'Transcontinental'; YK = 'Yukon'.

total germination (Day 21) of coated seed were as follows: $30 / 20=35 / 25=40 / 30>$ $25 / 15>45 / 35>20 / 10{ }^{\circ} \mathrm{C}$. Uncoated seed rankings were as follows: $30 / 20=35 / 25=$ $40 / 30>25 / 15=45 / 35>20 / 10{ }^{\circ} \mathrm{C}$.

A comparison of total germination percentages of uncoated seed for the five bermuda grass cultivars (Fig. 1) tested showed germination, in general, was highest at the $30 / 20$ or $35 / 25^{\circ} \mathrm{C}$ temperature regimes. The higher and lower temperature extremes tested negatively affected germination. 'Arizona common', 'Transcontinental', and 'Princess 77' generally had greater germination compared with 'Rivera' at all temperature regimes.

\section{Discussion}

Under optimal controlled temperatures, commercial coating does not have a significant effect on bermudagrass germination. When viewed as a whole, the total germination was not different between coated and uncoated seed at all three counting intervals. Although a commercially applied seedcoating may help decrease damping off caused by Pythium or Rhizoctonia species, reduce seed loss from feeding birds or insects, and reduce planting rate error (Rodgers, 2003), the experimental results indicate uncoated SB will have the same germination results as coated SB under the conditions tested.

Although seedcoat and temperature affect bermudagrass seed germination (Table 1), based on uncoated bermudagrass seed germination results, it is evident genetics have an integral role in germination (Fig. 1). For example, 'Riviera' exhibited the lowest germination of all the cultivars at each temperature regime with peak germination occurring at 30 and $35{ }^{\circ} \mathrm{C}$ regimes. In comparison, 'Yukon' had a wider tolerance to temperature in terms of consistent germination between $60 \%$ to $75 \%$ at 25 to $45{ }^{\circ} \mathrm{C}$. The remaining cultivars of 'Princess 77', 'Transcontinental', and 'Arizona Common' peaked with germination between
25 and $35^{\circ} \mathrm{C}$ before germination rates declined at higher temperatures. It appears that although new SB cultivars have been selected for turf quality traits, there has been little advancement in seed germination. Cultivar rankings from this experiment agree with the findings of Sandlin et al. (2006).

The science of seedcoating does not appear to be completely understood for all species. A review of literature shows negative to no effect of seedcoating on germination is as common as seedcoating having a positive effect. Very little is known about seedcoatings on bermudagrass; however, an early study reported a reduction in time to emergence of coated vs. uncoated bermudagrass (Hickey and Engleke, 1983). For 'Princess 77' and 'Transcontinental' at selective temperature regimes, coating had a significant positive effect on germination (Table 2). These findings are similar to positive findings of Vartha and Clifford (1973) testing lime coating, Greipsson (1999) testing cytokinin coating, and Scott (1975) testing a lime or talc coating. For 'Transcontinental', the significant positive increase in germination may be attributed to the $\mathrm{CaCO}_{3}$ contained in the coating. The coating contents for 'Princess 77 ' are proprietary, but nonetheless beneficial. In contrast, 'Riviera' showed a significant negative effect resulting from coating at two counting intervals and at two temperature regimes. The coating of 'Riviera' contains $\mathrm{CaCO}_{3}$ and two fungicides, fludioxonil and mefenoxam. The possibility exists that fludioxonil, mefenoxam, or the combination of the two fungicides may be causing a temperature-specific effect resulting in decreased 'Riviera' germination. The effects of these fungicides have been well studied in many species but are lacking in turfgrasses. In a study with fludioxonil-treated perennial ryegrass (Lolium perenne L.) and tall fescue (Festuca arundinacea Schreber), Leyronas et al. (2006) reported only one of 10 seed lots experienced significantly decreased germination resulting from the fungicide treatment. Furthermore, Kaur and Bishnoi (2011) examined the effect of mefenoxam on winter canola (Brassica napus L.) and found only a slight, non-significant reduction in germination of coated vs. uncoated seed. However, the addition of two fungicides could plausibly have an antagonistic effect on the 'Riviera' seed resulting in the significantly decreased germination.

The $30 / 20$ and $35 / 25{ }^{\circ} \mathrm{C}$ temperature regimes resulted in significantly greater germination at all counting intervals for every cultivar studied. Sandlin et al. (2006) also reported temperature specific SB germination differences, and the $30 / 20$ and $35 / 25{ }^{\circ} \mathrm{C}$ regimes can be considered an ideal environment for obtaining optimal germination of SB. Although AOSA recommends a day/ night regime of $35 / 20{ }^{\circ} \mathrm{C}$ for $C$. dactylon var. dactylon seed trials (AOSA, 1998), the results of the 21-d experiment indicate that $\mathrm{SB}$ also has a high germination percentage at the $30 / 20$ and $35 / 25{ }^{\circ} \mathrm{C}$ regimes. Additionally, the $30 / 20{ }^{\circ} \mathrm{C}$ findings related to coated SB correlate with the experimental reports of Ahring and Todd (1978) in which a trial with 14 SB cultivars resulted in establishing significantly greater germination with a day temperature of $30^{\circ} \mathrm{C}$ and a night temperature of $20{ }^{\circ} \mathrm{C}$.

For seeding considerations, environmental conditions closest to $30 / 20$ and $35 / 25{ }^{\circ} \mathrm{C}$ during the months of May through August in the southern United States will most likely result in optimal germination of SB. Because bermudagrass seed is very small, it is typically planted shallow in the soil (Evers and Parsons, 2010). These shallow soil temperatures should better correlate to air temperatures rather than temperatures at a 4-inch soil depth. The 35/25 and $30 / 20{ }^{\circ} \mathrm{C}$ temperature regimes correspond to average field temperatures for the months of June $\left(32 / 19^{\circ} \mathrm{C}\right)$, July $\left(33 / 22^{\circ} \mathrm{C}\right)$, and August $\left(33 / 21{ }^{\circ} \mathrm{C}\right)$ in Starkville, MS. Based on previous data (Munshaw et al., 2009; Patton 
et al., 2004a; Richardson et al., 2004) and the data generated in the current study, a seeding date during the month of June would be ideal for optimum germination.

The experimental results from Day 7 are quite important because environmental conditions favoring germination can be more accurately forecasted over a 7-d period vs. a 21-d period. Also, from a turf manager's perspective, controlling water, traffic, and nutrients in a germination zone can be more precisely accomplished over a short period. Lastly, weed pressure will become more severe with slower germination resulting in competition and the potential for a diminished grass stand (Evers and Parsons, 2010). Although speed of germination and seedling vigor are not necessarily related, because of the reasons listed, favoring cultivars displaying early germination may result in improved overall stand establishment and time to establishment. In addition, total germination percentages can help provide turf managers with accurate expected results leading to better management strategies.

For spring seeding considerations, the results from the $20 / 10{ }^{\circ} \mathrm{C}$ regime indicate that poor germination will occur until temperatures increase to provide a more favorable germination environment. Once day/night temperatures improve to the $25 / 15{ }^{\circ} \mathrm{C}$ regime, a significant increase in germination occurs vs. the $20 / 10{ }^{\circ} \mathrm{C}$ regime. Therefore, if considering germination alone, bermudagrass spring seeding is not recommended until soil surface temperatures at least reach $25 / 15^{\circ} \mathrm{C}$. These findings are in agreement with Evers and Parsons (2010) who reported temperatures below $25 / 15^{\circ} \mathrm{C}$ reduced bermudagrass germination. The authors go on to suggest that hulled bermudagrass seed should be planted from mid-April to June in the southeastern United States. However, Shaver et al. (2006) demonstrated that dormant seeding of 'Riviera' or 'Princess 77' in February and March in the southern United States still produces statistically similar coverage as more traditional April and May seeding dates. This again indicates that speed of germination is only one of several factors leading to a fully established stand.

For summer seeding considerations, the $45 / 35^{\circ} \mathrm{C}$ regime also displayed significantly less germination than the majority of temperature regimes. Although very few geographical locations experience the $45 / 35^{\circ} \mathrm{C}$ regime for 3 weeks, the $40 / 30{ }^{\circ} \mathrm{C}$ regime is present throughout many locations in the southern United States during the months of July and August. During these summer months when conditions are similar to the $40 / 30{ }^{\circ} \mathrm{C}$ regime, SB germination can be expected to decrease compared with $30 / 20$ and $35 / 25{ }^{\circ} \mathrm{C}$ temperature regimes. Mid- to late summer plantings in the southern United States will likely have reduced overall germination and diminished stolon/rhizome development that may result in reduced first winter survival (Munshaw et al., 2009; Richardson et al., 2004a). Therefore, summer seeding of bermudagrass at temperatures greater than $35 / 25^{\circ} \mathrm{C}$ is not recommended.
In late summer, when early germination is paramount to increase stolon development and promote first-year winter survival (Munshaw et al., 2001), seeding 'Yukon' and 'Transcontinental' may be good options as a result of quick germination at high temperatures $(70 \%$ at $7 \mathrm{~d}, 35 / 25^{\circ} \mathrm{C}$ ). If early germination results in quicker maturity, these cultivars may be able to produce stolons before dormancy, thus improving cold tolerance.

Although winter survival is very important to a turf manager, most new established turf areas are played on during the establishment year. Choosing a cultivar with fast germination may result in earlier stand maturity and thus increased usability. Matching cultivars with specific temperature regimes in the field may also lead to improved early cover and maturity. Ideally, however, turf managers will opt for field temperature regimes that will result in the longest possible growing season to improve winter survival.

\section{Literature Cited}

Ahring, R.M. and G.W. Todd. 1978. Seed size and germination of hulled and unhulled bermudagrass seeds. Agron. J. 70:667-670.

AOSA (Association of Official Seed Analysts). 2009. Rules for testing seed. Association of Official Seed Analysts, Ithaca, NY.

Baldwin, B.S., M. Cirtain, D.S. Horton, J. Ouellette, S.B. Franklin, and J.E. Preece. 2009. Propagation methods for Rivercane [Arundinaria gigantea $\mathrm{L}$. (Walter) Muhl.]. Castanea 74:300-316.

Barden, J.A., R.G. Halfacre, and D.J. Parrish. 1987. Plant science. McGraw-Hill, Inc., New York, NY.

Bonan, G. 2002. Ecological climatology. Cambridge University Press, New York, NY.

Bruneau, A.H., C.H. Peacock, and J.M. Dipaola. 1989. Cool season turfgrass establishment with fertilizer coated seed. Proc. of the Sixth International Turfgrass Research Conference. $p$. 263-265.

Bryan, W.E. 1918. Hastening the germination of bermuda grass seed by the sulfuric acid treatment. J. Amer. Soc. Agron. 10:279-281.

Campbell, N.A. 1993. Biology. The Benjamin/ Cummings Publishing Company, Inc., Redwood City, CA.

Copeland, L.O. and M.B. McDonald. 2001. Seed science and technology. Kluwer Academic Publishers, Norwell, MA.

Duble, R.L. 1989. Southern turfgrasses: Their management and use. TexScape, Inc., College Station, TX.

Evers, G.W. and M.J. Parsons. 2010. Temperature influence on seeded bermudagrass germination. The Texas J. of Agr. and Nat. Res. 22:87-93.

Greipsson, S. 1999. Seed coating improves establishment of surface seeded Poa pratensis used in revegetation. Seed Sci. and Tech. 27:1029-1032.

Harrington, G.T. 1923. Use of alternating temperatures in the germination of seeds. J. Agr. Res. 23:295-332.

Hickey, V.G. and M.C. Engleke. 1983. Effect of experimental seed coating on bermudagrass seed. TX Turfgrass Res. 1983:129-130.

ISTA (International Seed Testing Association). 2004. International rules for testing seed. Edition 2004. Extraordinary Meeting 2003, Glattbrugg, Switzerland. ISBN 3-906549-38-0.

Kaufman, G. 1991. Seed coating: A tool for stand establishment; a stimulus to seed quality. HortTechnology 1:98-102.
Kaur, G. and U.R. Bishnoi. 2011. Effect of polymer and pesticide seed coatings on winter canola seed germination at various osmotic potentials. World J. of Agr. Sciences 7:591-598.

Leinauer, B., M. Serena, and D. Singh. 2010. Seed coating and seeding rate effects turfgrass germination and establishment. HortTechnology 20:179-185.

Leyronas, C., B. Meriaux, and G. Raynal. 2006. Chemical control of Neotyphodium spp. Endophytes in perennial ryegrass and tall fescue seeds. Crop Sci. 46:98-104.

Morinaga, T. 1926. Effect of alternating temperatures upon the germination of seeds. Amer. J. Bot. 13:141-158.

Morris, K.N. 2002. National Turfgrass Evaluation Program. 1997 national bermudagrass test. NTEP No. 02-7. USDA, Beltsville, MD.

Munshaw, G.C., H.W. Philley, J.M. Goatley, P.D. Gerard, and B.R. Stewart. 2009. Timing of seeded bermudagrass establishment affects first winter survival. Intl. Turf. Soc. Res. J. 11:417-426.

Munshaw, G.C., D.W. Williams, and P.L. Cornelius. 2001. Management strategies during the establishment year enhance production and fitness of seeded bermudagrass stolons. Crop Sci. 41:1558-1564.

Newell, A.J., J.C. Hart-Woods, and F.M.E. Crossley. 1999. Investigation of the effects of fortiva seed treatment on the establishment of different grass species and mixtures. J. Sports Turf Res. Inst. 75:89-99.

Patton, A.J., G.A. Hardebeck, D.W. Williams, and Z.J. Reicher. 2004a. Establishment of bermudagrass and zoysiagrass by seed. Crop Sci. 44:2160-2167.

Patton, A.J., D.W. Williams, and Z.J. Reicher. 2004b. Establishing seeded bermudagrass. Golf Course Mgt. December:62-66.

Richardson, M.D. and K.W. Hignight. 2010. Seedling emergence of tall fescue and kentucky bluegrass, as affected by two seed coating techniques. HortTechnology 20:415-417.

Richardson, M.D., D.E. Karcher, and J.W. Boyd. 2004a. Seeding date and cultivar affect winter survival of seeded bermudagrasses. USGA Turfgrass and Environmental Research Online 3:1-8.

Richardson, M. D., D. E. Karcher, P. Berger, and J. W. Boyd. 2004b. Utilizing improved seeded bermudagrass on transition zone sports fields. Acta Hort. 661, ISHS, $1^{\text {st }}$ IC on Turfgrass. p. 369-374.

Rodgers, C. 2003. You've come a long way, bermuda. Golf Course Mgt. August:91-95.

Sandlin, T., G.C. Munshaw, H.W. Philley, B.S Baldwin, and B.R. Stewart. 2006. Temperature affects germination of seeded bermudagrasses. Agron. Abstr. 98:CD-ROM (abstr.)

Scott, D. 1975. Effects of seed coating on establishment. N. Z. J. Agr. Res. 18:59-67.

Serena, M., B. Leinauer, R. Sallenave, M. Schiavon, and B. Maier. 2012. Media selection and seed coating influence germination of turfgrasses under salinity. HortScience 47:116-120.

Shaver, B.R., M.D. Richardson, J.H. McCalla, D.E. Karcher, and P.J. Berger. 2006. Dormant seeding of bermudagrass cultivars in a transitionzone environment. Crop Sci. 46:1787-1792.

Steinbauer, G.P. and B. Grigsby. 1957. Interaction of temperature, light and moistening agent in the germination of weed seeds. Weeds. 5:175182.

Vartha, E.W. and P.T.P. Clifford. 1973. Effects of seed coating on establishment and survival of grasses, surface-sown on tussock grasslands. New Zealand J. of Expt. Agr. 1:39-43. 